\title{
Numerical Investigation on Effect of Immersed Blade Depth on the Performance of Undershot Water Turbines
}

\author{
Nor Fadilah Yah ${ }^{1}$, Idris Mat Sahat ${ }^{1}$ and Ahmed Nurye Oumer ${ }^{1}$ \\ ${ }^{1}$ Faculty of Mechanical Engineering, Universiti Malaysia Pahang, 26600 Pekan, Pahang, Malaysia.
}

\begin{abstract}
Energy, especially electricity, plays a vital role in global social and economic development. High annual rain rate in Malaysia seems a good potential for electricity generation especially through small hydro powers. Undershot water turbines are one of the hydropower turbines used for many years. However, the effect of blade depth immersed in the flowing water is not fully investigated. Therefore, the purpose of this paper is to study the effect of immersed blade depth for straight blade undershot water turbine in power generation by using Computational Fluid Dynamics (CFD) method. ANSYS CFX 15.0 was used to perform three dimensional analysis under steady state, incompressible, and non-isothermal conditions. The water wheel with number of blades of 6 and four different immersed depth was applied for each simulation. There are four different immersed depth was applied to each simulation, which are $20 \mathrm{~mm}, 40 \mathrm{~mm}, 60 \mathrm{~mm}$ and $80 \mathrm{~mm}$. From the simulation result, it was found that the optimum immersed depth is $40 \mathrm{~mm}$ where the torque load and power generated were 0.264 N.m and 1.318 Watt respectively.
\end{abstract}

\section{Introduction}

Energy plays a vital role in global social and economic development. The demand of energy has increased as a result of the industrial, domestic and agricultural activities that have been grown rapidly in order to fulfill the user needs.

Hydropower is one of the renewable energy resources which is getting popular and raising attention of many researchers. There are three types of hydropower technologies for rural or off-grid application which are mini-hydro, micro-hydro and pico-hydro. These hydropower technologies differ based on their requirement of suitable flow rate and head [ $\underline{5}]$.

Recently, Pico hydro become attractive because of its sustainability, cleanness and ability to generate power in low head area [6]. The water current turbine are very suitable for the rural electrification because of many advantages such as low head application, pollution free and economical [7]. The vertically mounted undershot wheel employs only the potential energy of the water as the driving force. The idea of utilizing potential energy instead of kinetic energy of the low head water in rivers was noticed by a French engineer, Poncelet []ㅡ.

Undershot water wheel could operate in very small head differences of $0.5 \mathrm{~m}$ to $2.5 \mathrm{~m}$ and large flow volume ranging from 0.5 to $0.95 \mathrm{~m}^{3} / \mathrm{s}$ per $\mathrm{m}$ width. The water enters the wheel's blade. The wheel will rotate as a result of reaction between water and lowest paddles at the bottom of wheel. Undershot water wheel is suitable for flat country like Malaysia because it almost has no interest on the head and can be operates in shallow water. Besides that, it can also be installed on the floating platform and portable [9]. Compared to water turbine, undershot water wheel has simpler design and can be operated in river with very small head and speed. However, the effect of blade depth immersed in the flowing water is not fully investigated. Therefore, the purpose of this study is to study the effect of immersed blade depth for straight blade undershot water turbine in power generation by using CFD method. ANSYS CFX 15.0 was used to perform three dimensional analyses under steady state, incompressible, and non-isothermal conditions.

\section{Numerical Model}

\subsection{Governing equations and Computational Domain}

Numerical simulations were performed using finite volume software called ANSYS CFX in three dimensional steady flow analysis. Flow equations in ANSYS CFX consist of equation of continuity and the Navier-Stokes equation. In this section, the numerical models for the turbine blade and river together with the 
boundary conditions imposed for different immersed blade depths simulations will be described.

The turbine blades considered for this study are straight type blades as shown in Figure 1 with overall dimensions $200 \mathrm{~mm}$ in diameter and width of $150 \mathrm{~mm}$. Each paddle wheel has area of $70 \mathrm{~mm}(\mathrm{H}) \times 150 \mathrm{~mm}(\mathrm{~W})$ with six number of paddles. The turbine is partially immersed in the flowing fluid (river) which is assumed to have constant flow velocity. The river flow field is considered to be incompressible, non-isothermal and behaves as Newtonian fluid (neglecting the effects of slurries inside the river). Therefore, the general forms of the mass and momentum equations can be written as:

$$
\begin{aligned}
& \frac{\partial \rho}{\partial t}+\nabla \cdot(\rho \mathrm{u})=0 \\
& \rho \frac{\partial}{\partial t}(\mathrm{u})+\rho \nabla \cdot(\mathrm{uu})=-\nabla p+\nabla \cdot \tau+\rho \mathrm{g}
\end{aligned}
$$

Where $\mathrm{u}$ is the velocity vector, $\rho$ is the density of water and $p$ the hydrostatic pressure. The term $\tau$ represents the total shear stress due to viscosity and $g$ is the gravity vector.

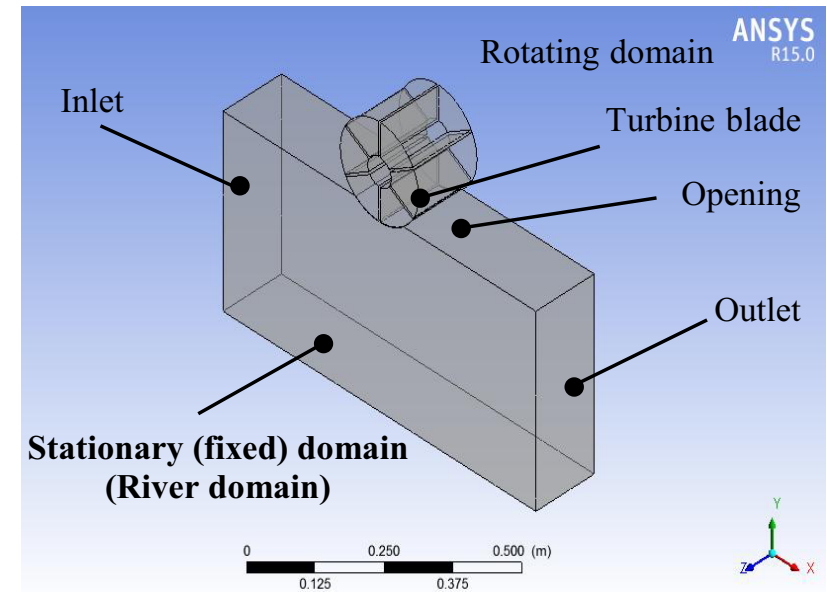

Figure 1: Schematic of turbine blade system considered in this study

\subsection{Mesh Generation}

The mesh generation was done by using Ansys-ICEM CFD. This software is not only effectively able to mesh large and complex models but also can provide advanced size function of the grid. Basically, computational mesh are classified into structured mesh and unstructured mesh [10]. Structured meshes are not preferred for complex geometries but it is more efficient in terms accuracy, CPU time and in most cases preferable. Unstructured mesh are preferable for complex geometries but the size difference between two adjacent elements can be large thus affect its numerical accuracy.

In this study, the simulation domain was divided in tow two parts; rotating and stationary parts. The stationary domain represents the domain for control surfaces of upstream and downstream region of the river. The rotating (turbine blade) domain meshed with advanced size function "proximity and curvature" and consist mainly of tetrahedral elements with 658948 numbers of elements. Table 1 summarizes the computational grids of both domains at various immersed blade depths. The stationary domain which represent the upstream and downstream regions were meshed with advanced size function turned off and consist mostly hexahedral elements with some tetrahedral, prismatic and wedges element type as shown in Figure 2.

Table 1: Computational grids for rotating and stationary domains at various immersed blade depths

\begin{tabular}{|c|c|c|c|}
\hline \multirow{2}{*}{$\begin{array}{c}\text { Immersed } \\
\text { depth } \\
\text { (mm) }\end{array}$} & \multirow{2}{*}{$\begin{array}{l}\text { Immersed } \\
\text { radius ratio }\end{array}$} & \multicolumn{2}{|c|}{ Number of elements } \\
\cline { 3 - 4 } & $\begin{array}{c}\text { Rotating } \\
\text { domain }\end{array}$ & $\begin{array}{c}\text { Stationary } \\
\text { domain }\end{array}$ \\
\hline 20 & 0.20 & 658948 & 6590 \\
\hline 40 & 0.40 & 658948 & 6909 \\
\hline 60 & 0.60 & 658948 & 6879 \\
\hline 80 & 0.80 & 658948 & 7039 \\
\hline
\end{tabular}

(a)
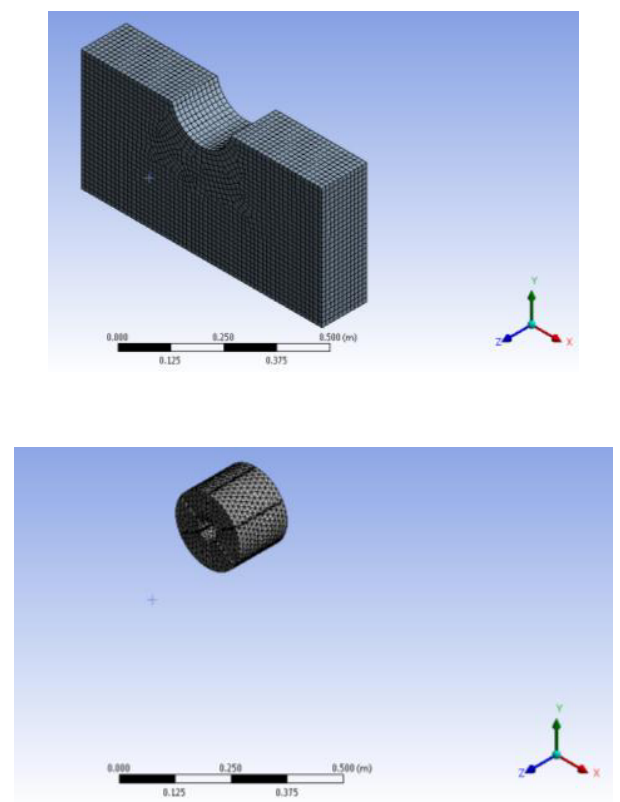

(b)

Figure 2: (a) Structured mesh for the stationary domain (b) Unstructured mesh for the rotating domain

\subsection{Boundary Conditions}

The simulation is for the straight blades turbine which consists of 6 blades and rotates at $5 \mathrm{rad} / \mathrm{s}$. The inlet flow velocity of the river is considered to be $0.5 \mathrm{~m} / \mathrm{s}$ (laminar flow). Control surfaces are established at a distance of twice the diameter of the turbine in the direction of upstream and downstream from the turbine center [1]. Besides that, the top surface of the computational domain was permeable to the atmosphere by applied with the entrainment with zero gradients. Meanwhile, no slip condition was applied to all other walls. The boundary of 
stationary and rotating domains were joined by using rotational periodicity method. The volume fraction of water (VFW) and volume fraction of air (VFA) were defined by using step functions as:

$$
\begin{aligned}
& V F W=\operatorname{step}((y-h) / 1[m]) \\
& V F A=1-V F W
\end{aligned}
$$

Where, $y$ is the coordinate of the height direction and $h$ is the depth of the river water. Other conditions include, free outflow with a relative gauge pressure of $0 \mathrm{~Pa}$ for the outlet boundary and rotational speed was applied to the rotating domain.

\section{Result and Discussion}

\subsection{Flow Patterns around Blade Surface}

Figures 3 and 4 show the steady flow velocity vector and pressure contour for various immersed blade heights. The velocity vectors and pressure contours for each immersed depth was compared. From the simulation result, it can be clearly seen that the as the blade depth increases the number of blades in contact with the flowing water increases. At blade depth of $60 \mathrm{~mm}$, surface area of the second blade in contact with the flowing fluid is higher that the recirculation contact area. This makes the back pressure to be higher the flow pressure for the second immersed blade. On the other hand, the effect of reverse pressure due to recirculation is negligible for $80 \mathrm{~mm}$ blade depth. The pressure difference between front and back surface of blade leads to the higher power generation. For blade depths $20 \mathrm{~mm}$ and $40 \mathrm{~mm}$, since the velocity of blade region that immersed in the water are higher than the air region which have higher volume fraction of air, the effect of reverse pressure due to recirculation of air is negligible.

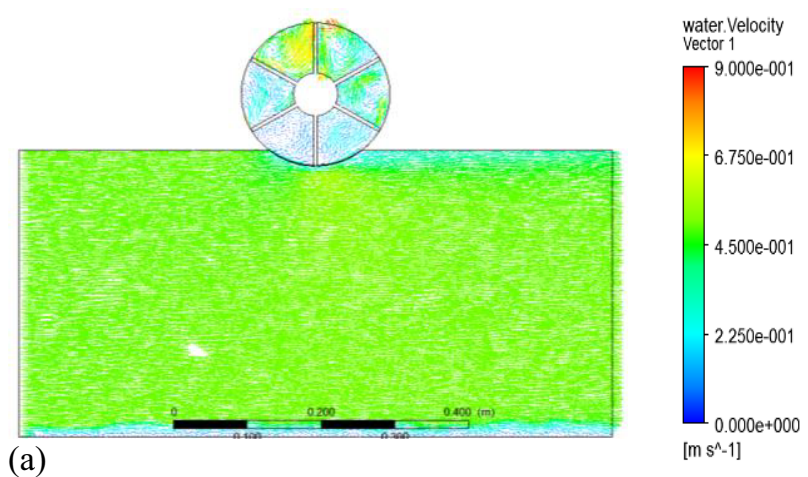

(a) $\left[\mathrm{m} \mathrm{s}^{\mathrm{n}-1]}\right.$

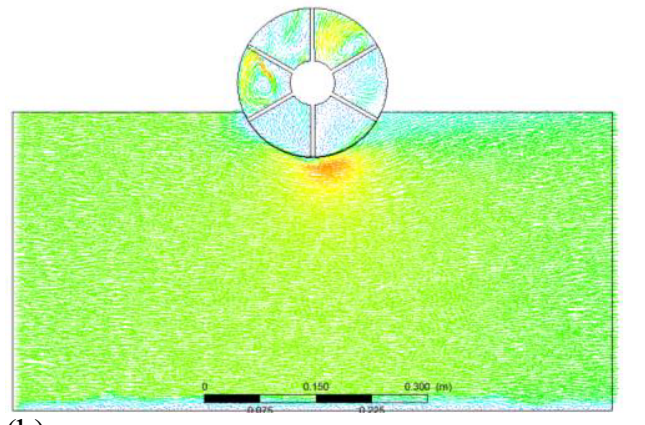

(b)

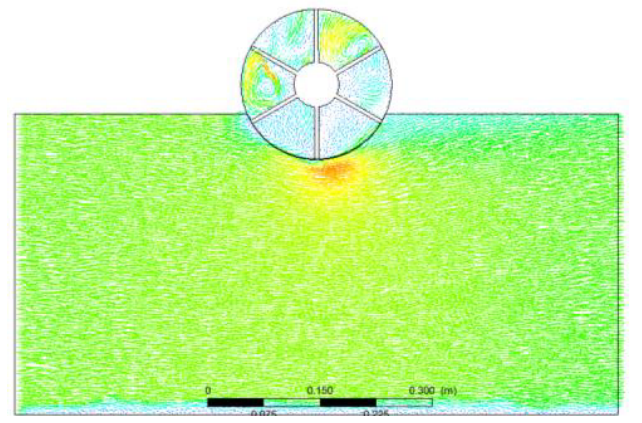

(c)

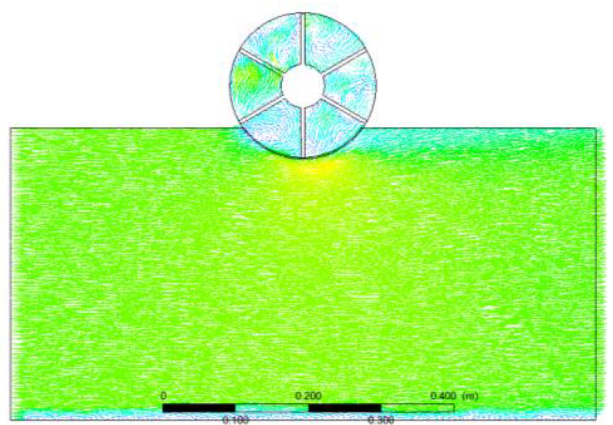

(d)

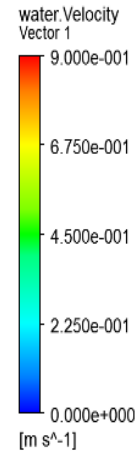

water.Velocity Vector 1

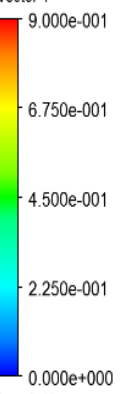
[m s^-1]

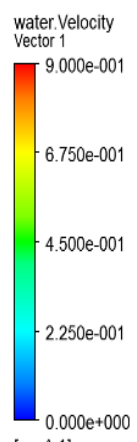

Figure 3: Velocity vector for different immersed blade depths (a) $80 \mathrm{~mm}$ (b) $60 \mathrm{~mm}$ (c) $40 \mathrm{~mm}$ (d) $20 \mathrm{~mm}$

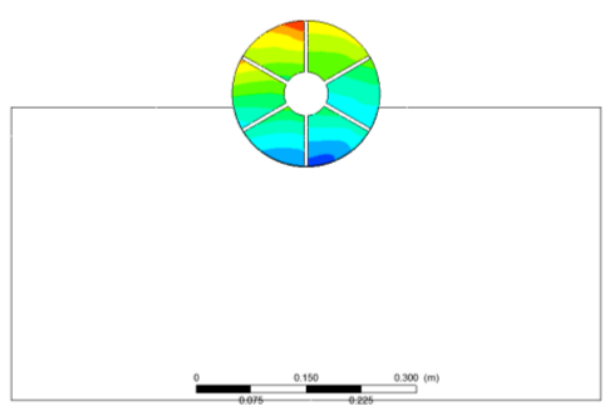

(a)

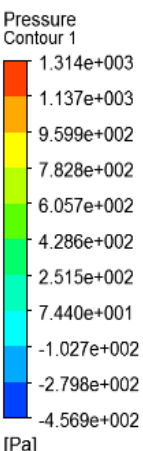



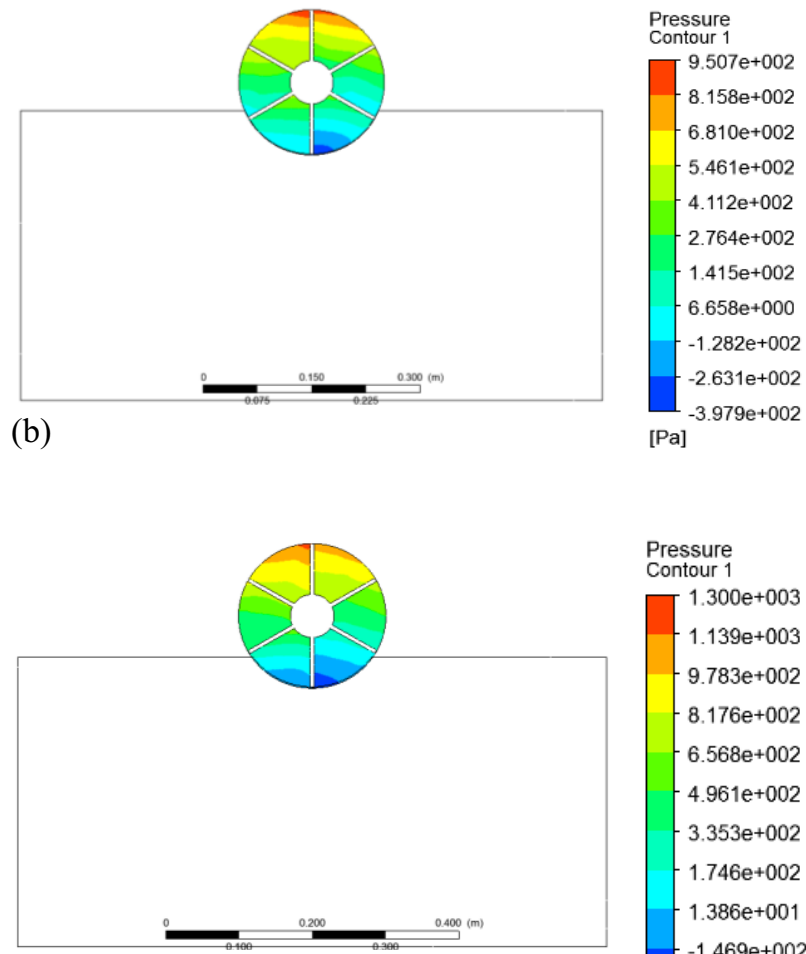

(c)

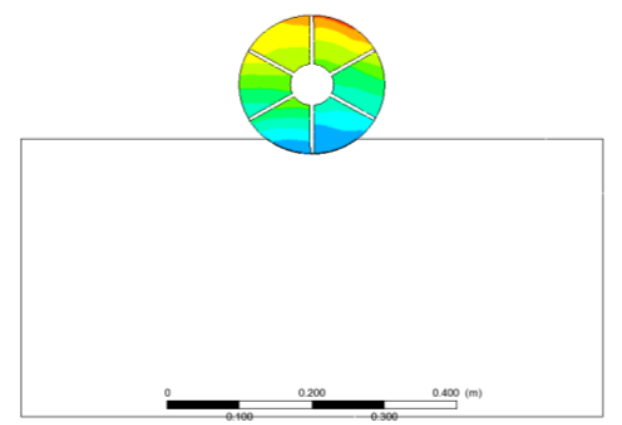

(d)

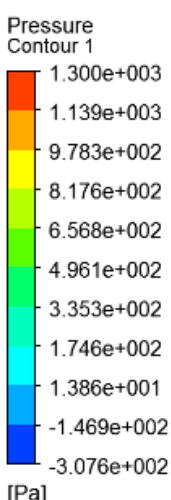

$[\mathrm{Pa}]$

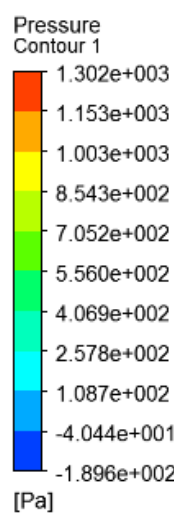

$[\mathrm{Pa}]$

Figure 4: Pressure contours for different immersed blade depths (a) $80 \mathrm{~mm}$ (b) $60 \mathrm{~mm}$ (c) $40 \mathrm{~mm}$ (d) $20 \mathrm{~mm}$

Figure 5 show the peak pressure, $\mathrm{p}$ acted on the blade immersed in the water. The value of peak pressure was increased when the immersed depth increased. As can be seen in Figures 6, power is varied with the immersed blade depth. It was found that the maximum power was generated when the immersed radius was $40 \mathrm{~mm}$ and the torque load at this depth was 0.264 N.m. When immersed depth increased, power also increased initially until optimum immersed depth which is $40 \mathrm{~mm}$ before decreasing. Besides that, the power coefficient for $40 \mathrm{~mm}$ immersed depth is the highest as shown in the Figure 7. This may happen due to the drag force generated when large area was immersed in the water. The obstacles due to the drag force generated are less in the $40 \mathrm{~mm}$ immersed radius.

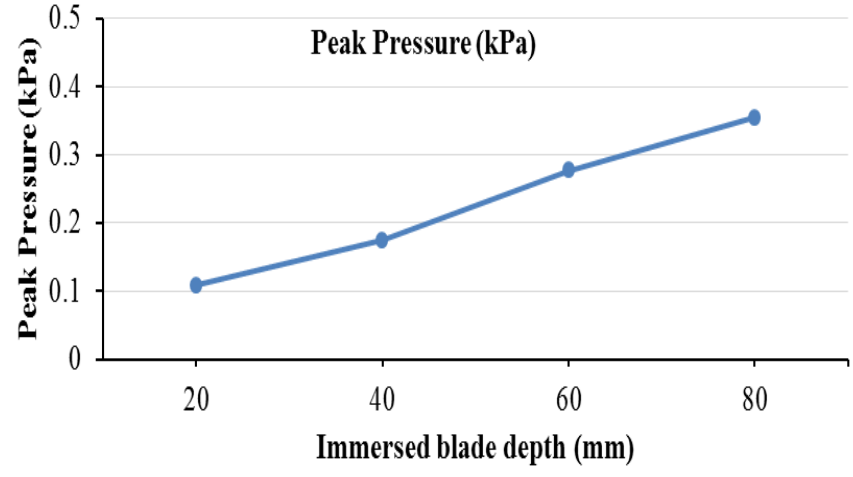

Figure 5: Peak pressure, p, for different immersed blade depths

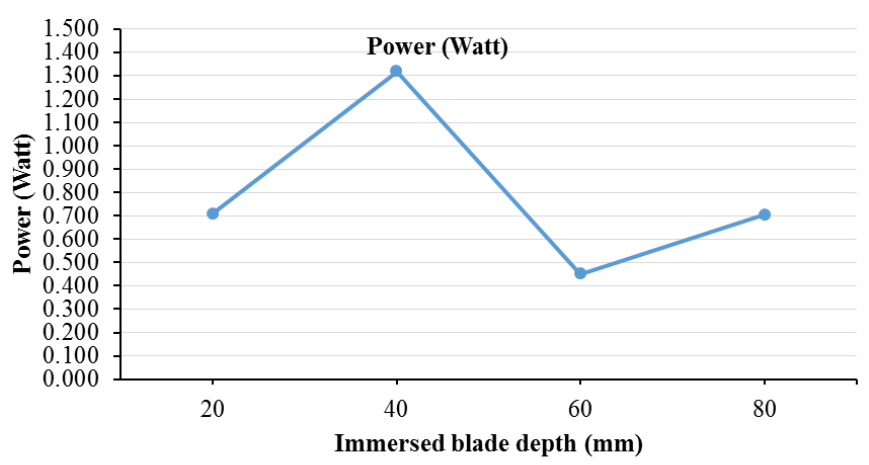

Figure 6: Variation of Power, $\mathrm{P}$ based on immersed depth

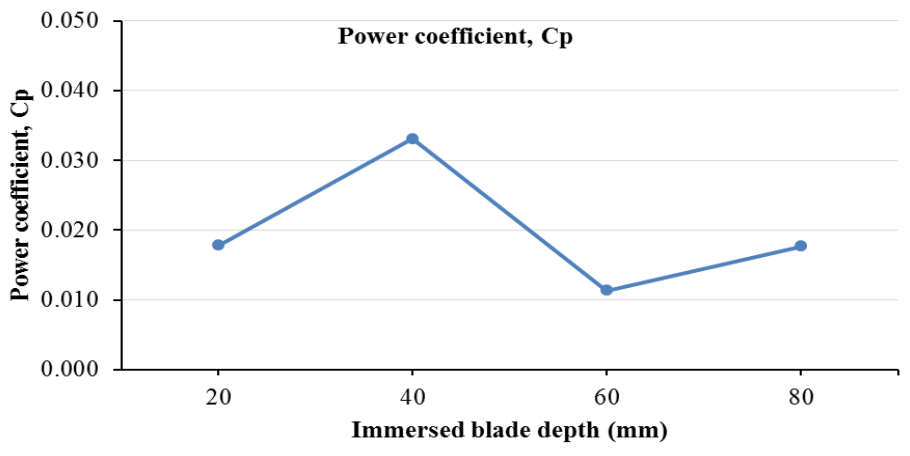

Figure 7: Power coefficient, $\mathrm{Cp}$ for different immersed blade depths

\section{Conclusion}

The performance of straight blade water turbine was numerically investigated. From the simulation, the performance of the undershot water turbine with different immersed depth was observed. The maximum power generation was generated when the immersed depth of the floating water turbine is $40 \mathrm{~mm}$. The value of maximum power generated at this depth is 1.32 Watt. However, the generated power is very small to light up even a single house hold bulb. Therefore, a mechanism to increase the flow velocity of the river should be done in order to increase the power generation from the turbine. 


\section{Acknowledgement}

The authors would like to thank Universiti Malaysia Pahang for providing necessary assistance and Ministry of Higher Education for providing financial support under FRGS project number RDU140127.

\section{References}

1. N.L. Panwar, S.C. Kaushik, and S. Kothari, Role of renewable energy sources in environmental protection: A review. Renewable and Sustainable Energy Reviews, 2011. 15(3): p. 15131524.

2. K. Beckman, Renewable Sources Provide Over 20\% Of Global Power Production. 2014; Available from: http://cleantechnica.com/2014/06/05/ren ewable-sources-global-powerproduction/.

3. I. Yüksel, Hydropower for sustainable water and energy development. Renewable and Sustainable Energy Reviews, 2010. 14(1): p. 462-469.

4. A.T. Din, M.Y. Othman, and M.Y. Yaakob, Harvesting Energy from Flood Mitigation Ponds using Water Wheel. 2011: Solo Java.

5. L. Barelli, et al., Mini-hydro: A design approach in case of torrential rivers. Energy, 2013. 58: p. 695-706.

6. L. Sule, I.N.G.W., R. Soenoko, S. Wahyudi, Performance of a Straight Bladed Water Current Turbine. Advances in Natural and Applied Sciences, 2013.

7. P. Maher, N.P.A. Smith, and A.A. Williams, Assessment of pico hydro as an option for off-grid electrification in Kenya. Renewable Energy, 2003. 28(9): p. 1357-1369.

8. G. Muller, Water Wheels as a Power Source. The Queen's University of Belfast p. 1-9.

9. S.R. Turnock, G.M., R. F. Nicholls-Lee, S. Denchfield, S. Hindley, and a.S.S. R. Shelmerdine. Development of a floating tidal energy system suitable for use in shallow water. in Proceedings of the 7th European Wave and Tidal Energy Conference,. 2007. Porto, Portugal.
10. R. Iovanel, Numerical simulation of the Flow Through Kaplan Draft tube, in Department of Engineering Sciences and Mathematics. 2014, Luleå University of Technology. 